\title{
Malignant renal schwannoma in a cat
}

\author{
Monier Sharif $^{1}$, Adel Mohamed ${ }^{1, *}$ and Manfred Reinacher ${ }^{2}$ \\ ${ }^{l}$ Department of Pathology and Anatomy, Faculty of Veterinary Medicine, University of Omar Al-Mukhtar, Al-Beida, \\ Libya \\ ${ }^{2}$ Institute for Veterinary Pathology, Justus-Liebig-University, Frankfurter Str. 96, 35392 Giessen, Germany
}

\begin{abstract}
A nine-year-old male European shorthair cat with rapidly enlarging mass at the left kidney doubted to be malignant was presented. The purpose of this study is to present the clinical, radiological and pathological findings of a primary renal tumor in the cat. Grossly, the mass mostly encapsulated the kidney. Histologically, excisional biopsy showed worrying histological features. A sarcoma-like tumor composed mainly of neoplastic spindle-shaped cells. Neoplastic nodules of aggregations of fusiform cells arranged in multidirectional bundles. Immunohistochemically, several immunohistochemical satins (melan-A, S-100, vimentin, actin, desmin, cytokeratin, neurofilament, melan-A, NSE, synaptophysin, chromogranin, Glial Fibrillary Acidic Protein GFAP, Collagen IV and CD99) were used to differentially diagnose the mass. The stained neoplastic sections positively tested to S-100, but negative to the other aforementioned immunohistochemical stains. Immunohistochemistry with S-100 antibody staining showed an unusually strong positive reaction throughout the tumor cells. Based on our comparative diagnosis relative to other tumors, in addition to the progressive clinical signs, histopathological and immunohistochemical results, this case was presumptively diagnosis as a malignant schwannoma. According to our investigation of the relevant literature, this study of malignant renal Schwannoma (malignant peripheral nerve sheath tumor) is a highly rare case not previously characterized in a cat.
\end{abstract}

Keywords: Cat, Immunohistochemistry, Kidney, Schwannoma, Tumor.

\section{Introduction}

There are a few reports of schwannomas in cats: in the oral cavity (Boonsriroj et al., 2014), in the head (Watrous et al., 1999), in the forelimb (Tremblay et al., 2005), and in the eye (Evans et al., 2010). Primary renal tumors are uncommon in domestic animals, so that only $12 \%$ of renal tumors are primary, while $88 \%$ are secondary. In general, $99 \%$ of renal tumors are malignant, $77 \%$ of which are epithelial and 23\% mesenchymal in origin. Renal tumors of neural origin are extremely rare (Meuten, 2002). According to our survey, only one case of renal tumor from neural origin has been reported in a cat (Jones et al., 1995).

Schwannoma is a tumor that arises from the Schwann's cells that are present among the cell types that form the nerve sheath. Malignant Schwannoma is part of a larger group of rare malignant peripheral nerve sheath tumors (MPNSTs) which are also called soft tissue sarcomas or neurofibrosarcomas (Rapini et al., 2007).

\section{Case details}

A 9-year-old male European shorthair male, castrated, cat was referred for clinical investigation. Initial diagnosis showed that the cat suffered from loss of appetite and low water intake with abdominal distension. Radiography and ultrasonography investigations revealed a mass approximately $15 \mathrm{~cm}$ in diameter within the left kidney. The cat was admitted for nephrectomy and the excised specimen was submitted for histopathology investigation at the Institute for Veterinary Pathology, Justus-LiebigUniversity, Giessen, Germany. No information on the cat after performing surgery.

The kidney together with the tumor mass were fixed in neutral buffered $10 \%$ formalin solution. A specimen from the tissue was processed, embedded in paraffin, sectioned at $4 \mu \mathrm{m}$ thickness and stained with Haematoxylin and Eosin (H\&E). Other sections were stained with Periodic Acid Schiff Stain (PAS), Azan trichrome stain and Warthin-Starry (WS) stain.

Immunohistochemistry was performed using polyclonal rabbit anti-S-100 antibody (Z0311 DAKO Co.). Anti-S-100 has strong tendency to positively react with most melanocytic tumors, Schwannomas, ependymomas, astrogliomas and glioblastomas, and sometimes with salivary gland tumors (Kawahara et al., 1988). Along with anti-S-100, and for differential diagnosis, the sample was stained with other antibodies for Neurofilaments, Glial fibrillary acidic protein (GFAP), Melan-A, NSE, Synaptophysin, Chromogranin (using the ABC method) and CD99 (monoclonal antibody 12E7 raised against the MIC2 protein). 
The gross examination, of formalin fixed kidney, showed a singular, roughly spherical encapsulated tumor mass in the left kidney. The mass was about 5.5 x $4.5 \times 4 \mathrm{~cm}$ superficially nodular, greyish-white in color, and greasy in texture. The tumor was detected at one pole of the kidney.

The tumor is well demarcated and distinguished from the normal renal tissue; it encapsulates the outside of the kidney and infiltrates inside the renal pelvis but it does not expand to the renal parenchyma (Fig. 1). The left adrenal gland could not be located. Right kidney was normal. Based on mass location and size, this tumor might be a primary tumor.

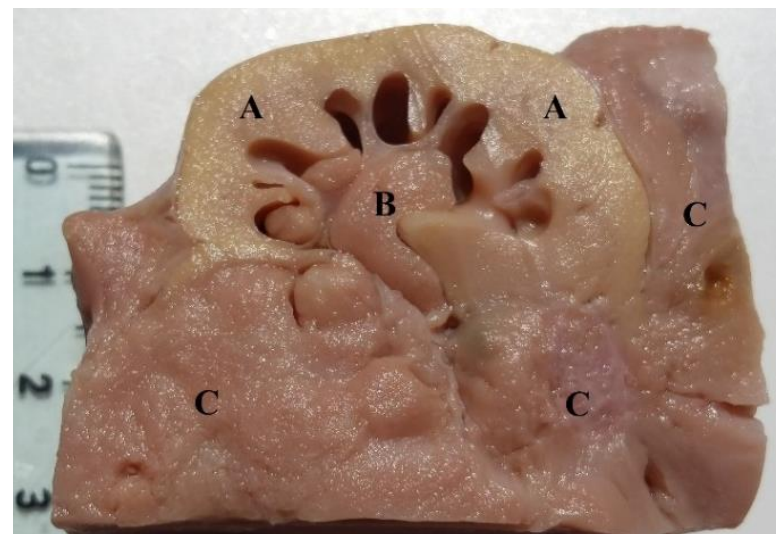

Fig. 1. Growth of tumor mass around and inside the hemisected kidney; tumor mass, in light brownish color, is encapsulating most of the kidney $(\mathrm{C})$, infiltrating inside the pelvis (B) without reaching the yellowish medulla and cortex (A).

Excised specimen was sent for histopathological examination which demonstrates thick capsules with loose tissues in some parts. Most of the neoplastic cells were arranged in dense bundles with increased cellularity like Antoni A areas of a classic schwannoma, and some in loosely arranged streams of cells like Antoni B (Fig .2).

In other parts of the tumor, single-cell groups were distributed as a fibro-vascular stroma which appeared to be mostly myxomatous.

The neoplastic cells appeared spindle-like or oval in shape with indistinct borders. The cytoplasm was eosinophilic with a moderate amount of PAS-positive fine granules. The nuclei, which appeared at the center as oval, elongated or spindle-like in shape, were hyperchromatic and finely stippled. The nucleoli were mostly singular and basophilic. Mitotic activity ranged from 3 to 5 per high power field (HPF). WS stain showed no evidence of external lamina to confirm the diagnosis of Schwannoma. The Azan stain showed a low to moderate amount of collagen fibres between the tumor cells. Renal tissue invasion, necrosis and hemorrhaging were evidence of malignancy.

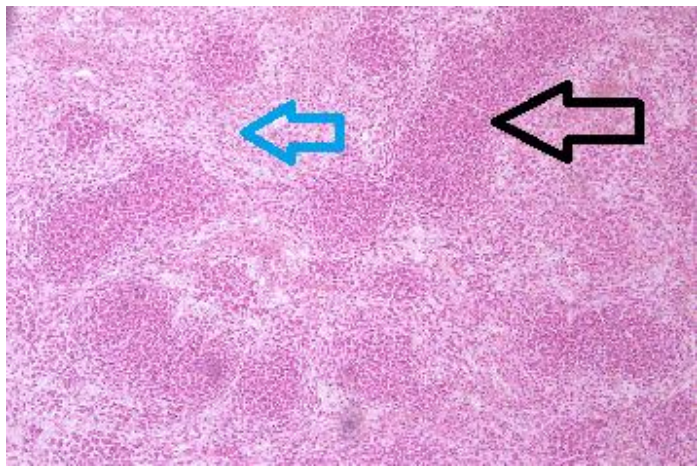

Fig. 2. Hematoxylin and eosin stained kidney tissue section reveals Neoplastic cells arranged in bundles and in streams (100x). The black arrow points at a dense area (Antoni A) and the blue arrow points at a looser area (Antoni B).

There were heterologous elements in form of cartilaginous islets (Fig. 3). Additionally, a mild multifocal lymphocytic interstitial nephritis was noted. Immunostaining showed that all tumor cells were strongly positive for anti-S-100 polyclonal antibodies (Fig. 4) and negative for Melan-A, Vimentin, actin, desmin, cytokeratin, neurofilament, melan-A, NSE, synaptophysin, chromogranin, Glial Fibrillary Acidic Protein GFAP, Collagen IV and CD99.

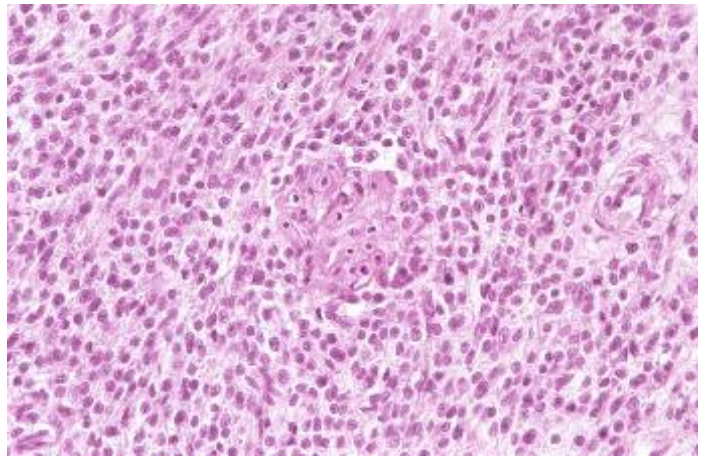

Fig. 3. Hematoxylin and eosin stained kidney tissue section shows spindle and oval Neoplastic cells with cartilaginous islets at the middle $(400 x)$.

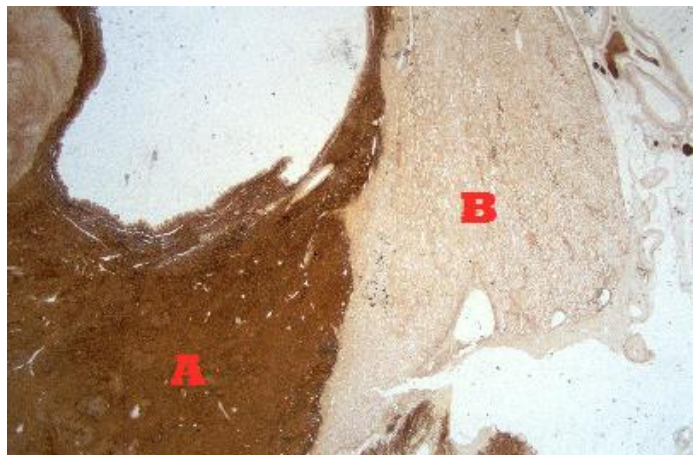

Fig. 4. Immunohistochemistry (IHC) shows tumor cells are diffusely immunoreactive for S-100 antibody (dark brown). (40x). The dark brown area is an indication for a positive reaction for S-100 antibody (A), where (B) indicates the negative reaction. 


\section{Discussion}

In such cases, morphological appearance might point at carcinoma as the primary suspect. Histological examination as well as immunohistochemistry, however, opposed this indication. Negative reaction with cytokeratin in particular excluded epithelial origin for this tumor. On the other hand, S-100 protein is normally expressed in cells originating from the neural crest (Schwann's cells, and melanocytes), as well as myoepithelial cells, chondrocytes, macrophages, adipocytes, keratinocytes, Langerhans cells, (Wilson et al., 1991; Coppola et al., 1998), dendritic cells, and some breast epithelial cells (Shinzato et al., 1995).

According to the literature, the expression of S-100 proteins varies between tumor types: $100 \%$ of Schwannomas and $100 \%$ of neurofibromas (with considerably lower stain intensity in neurofibromas than in schwannomas) $70-90 \%$ of melanomas and $50 \%$ of malignant peripheral nerve sheath tumors, paraganglioma stromal cells, histiocytoma and clear cell sarcomas (Nonaka et al., 2008).

Immunohistochemistry showed negative reaction with antibodies to Melan-A, which is normally expressed by melanocytes. The negative expression of Melan-A excluded melanoma as a candidate and limited the diagnosis to a tumor of neural origin. In using anti-S100 as an antibody indicator of neural origin, it is important to note that antibodies to S-100 family proteins react with many neural tumors outside the central nervous system, such as:

1- Schwannomas (Sabel and Teepen, 1995; Sarlomo-Rikala et al., 1998).

2- Neurofibroma (Karvonen et al., 2000).

3- Perineurioma: Fletcher (2007) stated that a small minority of perineuriomas show focal S100 positivity. However, Weidenheim and Campbell (1986), Kleihues and Sobin (2000), Rankine et al. (2004) and Boyanton et al. (2007) reported that perineuriomas were negative for S-100 proteins.

4- Melanocytic tumors (Gaynor et al., 1981; Orchard, 2000).

5- Adrenal Oncocytic Pheochromocytoma: Fletcher (2007) stated that only sustentacular cells within pheochromocytomas showed positive reaction with antibodies to S-100 proteins. However, Lin et al. (1998) and Mearini et al. (2012) reported that Pheochromocytomas showed negative reaction with antibodies to $\mathrm{S}-100$ proteins.

6- Liposarcomas (Andrion et al., 1991; McDonald et al., 2011).

7- Synovial sarcomas (Olsen et al., 2006).

8- Chondrosarcomas (rarely, and express cytokeratin) had positive reaction with antibodies to S-100 according to Oakley et al.
(2008), but negative reaction according to Swanson et al. (1990).

9- Ossifying fibromyxoid tumor of soft parts (Miettinen et al., 2008).

According to the WHO classification of neural origin tumors, Schwannomas diffusely, strongly and uniformly react with antibodies to S-100 protein, vimentin, and GFAP (Koestner, 1999). In this particular case, S-100 staining was strongly and diffusely positive but vimentin and GFAP staining were negative.

Ultrastructure of external lamina usually persists, in an attenuated and interrupted form, adjacent to cells of malignant Schwannomas (Ghadially, 2013). External lamina tends to be absent in Schwannomas (Erlandson and Woodruff, 1982). In this tumor, the external lamina was not clear and contained sporadic remnants.

As a result of the mutual expression of S-100 proteins by a variety of neural tumors to different degrees, and due to the absence of conclusive evidence, differential diagnosis was conducted to investigate and compare potential candidates with Schwannoma mainly based on the expression of S-100 and distinctive histopathological features:

Neurofibromas exhibit less reactivity (40\%) with S-100 antibody in comparison with Schwannomas, which react $100 \%$ with S-100 antibody. Neurofibromas were categorized into neuro and fibroblastic sub-tumor regions. Neuro components express only $40 \%$ of the tissue stained with S-100 antibody whereas the fibroblastic component does not express S-100 and reacts with antibodies to vimentin (Anton et al., 1994). In our study, cells were $100 \%$ S-100 positive. Microscopically, neurofibroma cells are elongated and arranged in interlacing bundles. Based on differential histological test and S-100 immune reaction, neurofibroma was a weak candidate for this case study. Perineurioma is an uncommon nerve sheath tumor expressing epithelial membrane antigen (EMA). Therefore, most Perineuriomas stain positively for EMA, Claudin-1, vimentin and collagen (Kleihues and Sobin, 2000) but negatively for S-100 protein and cytokeratin (Giannini et al., 1997; van Roggen et al., 2001). Although some other previously mentioned research studies stated that perineurioma cells do not express S-100 proteins, Fletcher (2007) reported that a small minority of cases may show positive reaction with S-100.

Histologically, perineurioma has been categorized into two types: intraneural and soft tissue perineuroma. Perineurioma cells appear well-differentiated and spindle-like in shape with stretched nuclei and eosinophilic cytoplasm. Perineuriomas are characterized by parallel cell arrangement to form concentric whorls known as onion bulbs (Hornick et al., 2009). 
This feature does not appear in the histological examination for this case. Both differences in histological appearance and the controversial reaction with S-100 antibody gave considerable reason for eliminating Perineurioma tumor in this case.

Malignant melanoma was initially a strong suspect due to the positivity of the tumor for S-100. For specificity, we applied immune staining using an antibody to Melan-A, which is a melanoma-specific marker (Smith et al., 2002) for which more than $67 \%$ of feline melanomas are cytoplasmatic positive (Ramos-Vara et al., 2002). Our case was negative for expression of Melan-A.

Ossifying fibromyxoid tumor of soft parts (OFMT) is an extremely rare tumor of bone and soft tissue (Graham et al., 2011). Although our survey of the literature showed no previous report of OFMT in domestic animals, previous studies in human revealed different expression levels of S-100 by ossifying fibromyxoid tumor cells: 73\% (Graham et al., 2011), 60\% (Folpe and Weiss, 2003) and 53\% (Gebre-Medhin et al., 2012). These expression levels were considerably lower in comparison with our study, in which the degree of expression of S-100 was unusually high, with almost $100 \%$.

Furthermore, our IHC results showed no expression of desmin which had been reported $38 \%$ in (Graham et al., 2011), 13\% (Folpe and Weiss, 2003) and $82 \%$ in OFMT (Gebre-Medhin et al., 2012).

Histologically, OFMT presents as a multi lobular growth consisting of nests of spherical-to-ovoid cells embedded in fibromyxoid stroma (Gebre-Medhin et al., 2012). It is also characterized by atypical necrosis and mitosis with high cellular activity rates $>2 \mathrm{MF} / 50 \mathrm{HPF}$ (Folpe and Weiss, 2003).

According to the known histological features of OFMT and the IHC results (S-100 and desmin) obtained in this study, OFMT was likely not the correct tumor in this case. However, theoretically, OFMT could not be completely excluded from the comparison with Schwann's cell tumors.

Adrenal oncocytic pheochromocytoma positively expresses chromogranin, synaptophysin, neuronspecific enolase, neurofilament, serotonin, bombesin, ACTH, vimentin, desmin, S-100 protein, and cytokeratins including AE1/3, CAM 5.2, cytokeratin 7, and cytokeratin 20. ( $\mathrm{Li}$ and Wenig, 2000). Gross appearance examination of our case showed that the tumor originated from the kidney pelvis whereas Pheochromocytoma originates from the medulla of the adrenal gland. In addition, according to our observations, Oncocytic pheochromocytoma usually stains with yellow in formalin fixation. This phenomenon was not observed in our case.

Liposarcomas express S-100 in fat cells and lipoblasts. PAS positive elements might be seen as well in some adipocytes and lipoblasts, which positively react with anti-vimentin but vary in intensity and might not react in poorly differentiated lesions due to lack of expression. Transition from low to high grade nonlipogenic morphology can occur within a welldifferentiated liposarcoma. Heterologous elements occur in $5-10 \%$ of cases with myogenic, osteo/chondrosarcomatous, or rarely angiosarcomatous elements. Myxoid liposarcoma (Van Roggen and Fletcher, 1999) and spindle cell liposarcoma (Dei Tos et al., 1994) were both reported as S-100 positive. In our case, no adipose cell differentiation was observed, and the diagnosis of liposarcoma can be easily excluded based on the histological appearance.

Diagnosis of schwannomas is based on presence of some features, including: (1) Antoni Type A or B histologic feature (Cordy, 1978). (2) Round cells with few cytoplasmic components, enclosed by a basal lamina (Erlandson and Woodruff, 1982). (3) Positive immunohistochemical staining to S-100 of neuronal origin (Wechsler et al., 1973; Vinores et al., 1984).

Generally, discrimination between benign and malignant schwannoma is sometimes challenging; since both kinds have comparable morphological features (Boonsriroj et al., 2014). Malignant schwannoma is usually densely packed arranged in patterns with high mitotic range (Pumarola et al., 1996). Whereas, benign schwannoma usually is small in size, grows superficially with low mitotic activities (Kindblom et al., 1998).

Although positive immunoreactivity for $\mathrm{S}-100$ is an indication of benign and most malignant Schwannomas (Matsunou et al., 1985), cells in this tumor showed malignant characteristics in histological examination, e.g. Antoni A and B patterns and neoplastic cells with different sizes and shapes.

\section{Conclusion}

From these comparisons, which were conducted based on the strong expression of $\mathrm{S}-100$ and from the exclusion of the aforementioned tumors, the findings of our investigation matched malignant schwannoma as the most likely diagnosis in this case. Unlike these malignant tumors, cellular schwannoma reveals a strong and diffuse reactivity for S-100. Figure 2 clearly shows two different groups of cells (Antoni patterns A and B); a looser area with low density of cells and interwoven dense cells with clear myxoid changes. Antoni patterns, in this case, may be a good indicator for malignant schwannoma versus benign schwannoma.

In addition, and in comparison with similar studies (Mandrioli et al., 2005; Cho et al., 2006; Boonsriroj et al., 2014; Duke et al., 2015), histomorphological and immunohistochemical means helped in reaching that malignant schwannoma is the final diagnosis in our case. 


\section{Conflict of interest}

The authors declare that there is no conflict of interests.

\section{References}

Andrion, A., Gaglio, A., Dogliani, N., Bosco, E. and Mazzucco, G. 1991. Liposarcoma of the thyroid gland. Fine-needle aspiration cytology, immunohistology, and ultrastructure. Am. J. Clin. Pathol. 95(5), 675-679.

Anton, E.S., Weskamp, G., Reichardt, L.F. and Matthew, W.D. 1994. Nerve growth factor and its low-affinity receptor promote Schwann cell migration. Nat. Acad. Sci. 91(7), 2795-2799.

Boonsriroj, H., Kimitsuki, K., Akagi, T. and Chun-Ho, P.A.R.K. 2014. Malignant epithelioid schwannoma of the oral cavity in a cat. J. Vet. Med. Sci. 76(6), 927-930.

Boyanton Jr, B.L., Jones, J.K., Shenaq, S.M., Hicks, M.J. and Bhattacharjee, M.B. 2007. Intraneural perineurioma: a systematic review with illustrative cases. Arch. Pathol. Lab. Med. 131(9), 13821392.

Cho, H.S., Kim, Y.S., Choi, C., Lee, J.H., Masangkay, J.S. and Park, N.Y. 2006. Malignant schwannoma in an American buffalo (Bison bison bison). J. Vet. Med. A. Physiol. Pathol. Clin. Med. 53(8), 432434.

Coppola, D., Fu, L., Nicosia, S.V., Kounelis, S. and Jones, M. 1998. Prognostic significance of p53, bcl2 , vimentin, and $S 100$ protein-positive langerhans cells in endometrial carcinoma. Hum. Pathol. 29(5), 455-462.

Cordy, D.R. 1978. Nervous system and eye. Tumors in Domestic Animals. Moulton, J.C. Ed. $2^{\text {nd }}$ ed., University of California Press, Berkeley, pp: 654660.

Dei Tos, A.P., Mentzel, T., Newman, P.L. and Fletcher, C.D. 1994. Spindle Cell Liposarcoma, A Hitherto Unrecognized Variant of Liposarcoma Analysis of Six Cases. Am. J. Surg. Pathol. 18(9), 913-921.

Duke, F.D., Teixeira, L.B.C., Galle, L.E., Green, N. and Dubielzig, R.R. 2015. Malignant uveal schwannoma with peripheral nerve extension in a 12-week-old color-dilute Labrador Retriever. Vet. Pthol. 52(1), 181-185.

Erlandson, R.A. and Woodruff, J.M. 1982. Peripheral nerve sheath tumors: an electron microscopic study of 43 cases. Cancer 49(2), 273-287.

Evans, P.M., Lynch, G.L. and Dubielzig, R.R. 2010. Anterior uveal spindle cell tumor in a cat. Vet. Ophthalmol. 13(6), 387-390.

Fletcher, C.D. 2007. Diagnostic Histopathology of Tumors, $3^{\text {rd }}$ ed. 1883 pp. in 2 volumes with 2 CDROMs. Churchill Livingstone Elsevier Limited, Philadelphia, PA, USA.
Folpe, A.L. and Weiss, S.W. 2003. Ossifying fibromyxoid tumor of soft parts: a clinicopathologic study of 70 cases with emphasis on atypical and malignant variants. Am. J. Sur. Pathol. 27, 421-431.

Gaynor, R., Irie, R., Morton, D., Herschman, H., Jones, P. and Cochran, A. 1981. S100 protein: a marker for human malignant melanomas? Lancet, 1(8225), 869-871.

Gebre-Medhin, S., Nord, K.H., Möller, E., Mandahl, N., Magnusson, L., Nilsson, J., Jo, V.Y., von Steyern, F.V., Brosjö, O., Larsson, O. and Domanski, H.A. 2012. Recurrent rearrangement of the PHF1 gene in ossifying fibromyxoid tumors. Am. J. Pathol. 181(3), 1069-1077.

Ghadially, F.N. 2013. Ultrastructural pathology of the cell and matrix: a text and atlas of physiological and pathological alterations in the fine structure of cellular and extracellular components. $3^{\text {rd }} \mathrm{Ed}$. Butterworth-Heinemann.

Giannini, C., Scheithauer, B.W., Jenkins, R.B., Erlandson, R.A., Perry, A., Borell, T.J., Hoda, R.S. and Woodruff, J.M. 1997. Soft-tissue perineurioma: evidence for an abnormality of chromosome 22, criteria for diagnosis, and review of the literature. Am. J. Surg. Pathol. 21(2), 164-173.

Graham, R.P., Dry, S., Li, X., Binder, S., Bahrami, A., Raimondi, S.C., Dogan, A., Chakraborty, S., Souchek, J.J. and Folpe, A.L. 2011. Ossifying fibromyxoid tumor of soft parts: a clinicopathologic, proteomic and genomic study. Am. J. Surg. Pathol. 35(11), 1615-1625.

Hornick, J.L., Bundock, E.A. and Fletcher, C.D. 2009. Hybrid schwannoma/perineurioma: clinicopathologic analysis of 42 distinctive benign nerve sheath tumors. Am. J. Surg. Pathol. 33(10), 1554-1561.

Jones, B.R., Alley, M.R., Johnstone, A.C., Jones, J.M., Cahill, J.I. and McPherson, C. 1995. Nerve sheath tumours in the dog and cat. N. Z. Vet. J. 43(5), 190196.

Karvonen, S.L., Kallioinen, M., Ylä-Outinen, H., Pöyhönen, M., Oikarinen, A. and Peltonen, J. 2000. Occult neurofibroma and increased S100 protein in the skin of patients with neurofibromatosis type 1: new insight to the etiopathomechanism of neurofibromas. Arch. Dermatol. 136(10), 12071209.

Kawahara, E., Oda, Y., Ooi, A., Katsuda, S., Nakanishi, I. and Umeda, S. 1988. Expression of Glial Fibrillary Acidic Protein (GFAP) in Peripheral Nerve Sheath Tumors: A Comparative Study of Immunoreactivity of GFAP, Vimentin, S-100 Protein, and Neurofilament in 38 Schwannomas and 18 Neurofibromas. Am. J. Surg. Pathol. 12(2), 115120. 
Kindblom, L. G., Meis-Kindblom, J. M., Havel, G. and Busch, C. 1998. Benign epithelioid schwannoma. Am. J. Surg. Pathol. 22, 762-770.

Kleihues, P. and Sobin, L.H. 2000. World Health Organization classification of tumors. Cancer 88(12), 2887.

Koestner, A. 1999. Histological classification of tumors of the nervous system of domestic animals. Armed Forces Institute of Pathology: American Registry of Pathology: World Health Organization Collaborating Center for Comparative Oncology.

Li, M. and Wenig, B.M. 2000. Adrenal oncocytic pheochromocytoma. Am. J. Surg. Pathol. 24(11), 1552-1557.

Lin, B.T.Y., Bonsib, S.M., Mierau, G.W., Weiss, L.M. and Medeiros, L.J. 1998. Oncocytic adrenocortical neoplasms: a report of seven cases and review of the literature. Am. J. Surg. Pathol. 22(5), 603-614.

Mandrioli, L., Gentile, A., Morini, M., Bettini, G. and Marcato, P.S. 2005. Malignant, solitary, nasopharyngeal schwannoma in a cow. Vet. Rec. 156(17), 552-553.

Matsunou, H., Shimoda, T., Kakimoto, S., Yamashita, H., Ishikawa, E. and Mukai, M. 1985. Histopathologic and immunohistochemical study of malignant tumors of peripheral nerve sheath (malignant Schwannoma). Cancer 56(9), 22692279.

McDonald, A.G., Dal Cin, P., Ganguly, A., Campbell, S., Imai, Y., Rosenberg, A.E. and Oliva, E. 2011. Liposarcoma arising in uterine lipoleiomyoma: a report of 3 cases and review of the literature. Am. J. Surg. Pathol. 35(2), 221-227.

Mearini, L., Del Sordo, R., Costantini, E., Nunzi, E. and Porena, M. 2012. Adrenal oncocytic neoplasm: a systematic review. Urol. Intern. 91(2), pp.125-133.

Meuten, D.J. 2002. Tumors of the urinary system. Tumors in Domestic Animals, $4^{\text {th }}$ Edition, pp: 509-546.

Miettinen, M., Finnell, V. and Fetsch, J.F. 2008. Ossifying fibromyxoid tumor of soft part--a clinicopathologic and immunohistochemical study of 104 cases with long-term follow-up and a critical review of the literature. Am. J. Surg. Pathol. 32(7), 996-1005.

Nonaka, D., Chiriboga, L. and Rubin, B.P. 2008. Differential expression of S100 protein subtypes in malignant melanoma, and benign and malignant peripheral nerve sheath tumors. J. Cutan. Pathol. 35(11), 1014-1019.

Oakley, G.J., Fuhrer, K. and Seethala, R.R. 2008. Brachyury, SOX-9, and podoplanin, new markers in the skull base chordoma vs chondrosarcoma differential: a tissue microarray-based comparative analysis. Mod. Pathol. 21(12), 1461-1469.
Olsen, S.H., Thomas, D.G. and Lucas, D.R. 2006. Cluster analysis of immunohistochemical profiles in synovial sarcoma, malignant peripheral nerve sheath tumor, and Ewing sarcoma. Mod. Pathol. 19(5), 659-668.

Orchard, G.E. 2000. Comparison of immunohistochemical labelling of melanocyte differentiation antibodies melan-A, tyrosinase and HMB 45 with NKIC3 and S100 protein in the evaluation of benign naevi and malignant melanoma. Histochem. J. 32(8), 475-481.

Pumarola, M., Anor, S., Borras, D. and Ferrer, I. 1996. Malignant epithelioid schwannoma affecting the trigeminal nerve of a dog. Vet. Pathol. 33, 434-436.

Ramos-Vara, J.A., Miller, M.A., Johnson, G.C., Turnquist, S.E., Kreeger, J.M. and Watson, G.L. 2002. Melan A and S100 protein immunohistochemistry in feline melanomas: 48 cases. Vet. Pathol. 39(1), 127-132.

Rankine, A.J., Filion, P.R., Platten, M.A. and Spagnolo, D.V. 2004. Perineurioma: a clinicopathological study of eight cases. Pathology 36(4), 309-315.

Rapini, R.P., Bolognia, J.L. and Jorizzo, J.L. 2007. Dermatology: 2-Volume Set. St. Louis: Mosby.

Sabel, L.H.W. and Teepen, J.L.J.M. 1995. The enigmatic origin of olfactory schwannoma. Clin. Neurol. Neurosurg. 97(2), 187-191.

Sarlomo-Rikala, M., Lahtinen, T., Andersson, L.C., Mie1tinen, M. and Knuutila, S. 1998. Different patterns of DNA copy number changes in gastrointestinal stromal tumors, lelomyomas, and schwannomas. Hum. Pathol. 29(5), 476-481.

Shinzato, M., Shamoto, M., Hosokawa, S., Kaneko, C., Osada, A., Shimizu, M. and Yoshida, A. 1995. Differentiation of Langerhans cells from interdigitating cells using CD1a and S-100 protein antibodies. Biotech. Histochem. 70(3), 114-118.

Smith, S.H., Goldschmidt, M.H. and McManus, P.M. 2002. A comparative review of melanocytic neoplasms. Vet. Pathol. 39(6), 651-678.

Swanson, P.E., Lillemoe, T.J., Manivel, J.C. and Wick, M.R. 1990. Mesenchymal chondrosarcoma. An immunohistochemical study. Arch. Pathol. Lab. Med. 114(9), 943-948.

Tremblay, N., Lanevschi, A., Doré, M., Lanthier, I. and Desnoyers, M. 2005. Of all the nerve! A subcutaneous forelimb mass on a cat. Vet. Clin. Pathol. 34(4), 417-420.

Van Roggen, G. and Fletcher, M. 1999. Myxoid tumours of soft tissue. Histopathol. 35(4), 291-312.

Van Roggen, J.F.G., McMenamin, M.E., Belchis, D.A., Nielsen, G.P., Rosenberg, A.E. and Fletcher, C.D. 2001. Reticular perineurioma: a distinctive variant of soft tissue perineurioma. Am. J. Surg. Pathol. 25(4), 485-493. 
Vinores, S.A., Bonnin, J.M., Rubinstein, L.J. and Marangos, P.J. 1984. Immunohistochemical demonstration of neuron-specific enolase in neoplasms of the CNS and other tissues. Arch. Pathol. Lab. Med. 108(7), 536-540.

Watrous, B.J., Lipscomb, T.P., Heidel, J.R. and Normal, L.M. 1999. Malignant peripheral nerve sheath tumor in a cat. Vet. Radiol. Ultrsound 40(6), 638-640.

Wechsler, W., Pfeiffer, S.E., Swenberg, J.A. and
Koestner, A. 1973. S-100 protein in methyl-and ethylnitrosourea induced tumors of the rat nervous system. Acta Neuropathol. 24(4), 287-303.

Weidenheim, K.M. and Campbell, Jr, W.G. 1986. Perineurial cell tumor. Virchows Arch. A. Pathol. Anat. Histopathol. 408(4), 375-383.

Wilson, A.J., Maddox, P.H. and Jenkins, D. 1991. CD1a and S100 antigen expression in skin Langerhans cells in patients with breast cancer. J. Pathol. 163(1), 25-30. 